\title{
A THEORETICAL ANALYSIS OF THE EXTRACTION OF HETEROCYCLIC ORGANIC COMPOUNDS FROM AN ORGANIC PHASE USING CHEMICALLY MEDIATED ELECTROCHEMICALLY MODULATED COMPIEXATION IN ION EXCHANGE POLYMER BEADS
}

\section{Kenan OZEKIN}

Deparment of Chemical Engineering University of Colorado Boulder, CO 80309-0424

\author{
Richard D. NOBLE ${ }^{1}$
}

Department of Chemical Engineering University of Colorado Boulder, CO 80309-0424

\author{
Carl A. KOVAL
}

Department of Chemistry and Biochemistry University of Colorado Boulder, CO 80309-0215

\section{DISCLAIMER}

\begin{abstract}
This report was prepared as an account of work sponsored by an agency of the United States Government. Neither the United States Government nor any agency thereof, nor any of their employees, makes any warranty, express or implied, or assumes any legal liability or responsibility for the accuracy, completeness, or usefulness of any information, apparatus, product, or process disclosed, or represents that its use would not infringe privately owned rights. Reference herein to any specific commercial product, process, or service by trade name, trademark, manufacturer, or otherwise does not necessarily constitute or imply its endorsement, recommendation, or favoring by the United States Government or any agency thereof. The views and opinions of authors expressed herein do not necessarily state or reflect those of the United States Government or any agency thereof.
\end{abstract}

\footnotetext{
1 Author whom correspondence should be addressed
} 


\begin{abstract}
A cyclical electrochemical process for the removal of heterocyclic organic compounds (pollutants) from an organic solvent using an ion-exchange polymer is analyzer. In this analysis, there are three main steps: In the first step, the polymer beads containing the active form of the complexing agent are contacted with the contaminated (feed) hydrocarbon phase. The pollutant diffuses into the beads and binds with the complexing agent which is in the reduced state. It is a fast reversible reaction. A non-linear partial differential equation with an ordinary differential equation on the boundary is derived to describe this step. The numerical results give the distribution of the pollutant in the bead and bulk phase as a function of time. For the second step, the beads which contain a pollutant are contacted with a waste (receiving) phase and a chemical mediator is then used to oxidize the complexing agent and to reduce its affinity towards the pollutant so that it can be released. The oxidation of the complexing agent is an irreversible reaction. This is a moving boundary problem with countercurrent diffusion. For each mole of mediator that goes into the bead, one mole of pollutant exits since each complexing agent binds one pollutant. A set of partial differential equations are derived to describe this step. The equations are solved analytically using a perturbation solution. The results show the pollutant distribution in the bulk phase and the pollutant distribution in the intemal phase for a given reaction front position. In addition, one also can calculate the mediator distribution in the bulk and internal phase. In the third step, the waste hydrocarbon phase is removed and a second chemical mediator is then used to reduce the complexing agent. The reduction of the complexing agent is also an irreversible reaction. A parial differential equation with two ordinary differential equations on the boundary describes this step. One ordinary differential equation defines how the bulk phase mediator concentration changes with time while the second defines the moving boundary position. The equations are solved using a perurbation method. The results give the position of the reaction front as a function of time. In addition, one can calculate the bulk and internal phase concentrations as a function of time.
\end{abstract}




\section{INTRODUCTION}

Insoluble materials which are capable of exchanging cations or anions are commonly called ion exchangers. They first were discovered by English agriculturist H.S. Thompson (Thompson. 1850) and applied by Robert Gans in a process of water softening (Gans, 1905). Since then, ion exchangers have been applied to other separations. These include recovery of valuable products through concentration or regeneration, for example, copper (Gerstner, 1953) and gold recovery (Davison, 1961), purification of solutions, for example, removal of iron from concentrated hydrochloric acid (Dorfner, 1972) and as acid or base catalysts (Astle, 1975).

The rate of ion exchange with reaction was first explored by Helfferich (Helfferich, 1965). He has developed the first detailed theoretical analysis of four different exchange reaction systems and has presented a collection of rate laws for each system under conditions of interparticle and external film diffusion rate control. Helfferich's theoretical analysis was later validated in a number of publications in different areas of ion exchange (Blickenstaff et al., 1967a; Blickenstaff et al., 1967b; Adams et al., 1969; Warner et al., 1970: Selim and Seagrave, 1973; Dana and Wheelock, 1974; Nativ et al., 1975; Holl, 1984; Schmuckler, 1984).

A process using an electrochemically reversed chemical complexation to remove organosulfur and nitrogen compounds from an organic phase has first been described by Koval et al. (1988). A cyciical contacting scheme is proposed: the compounds are first extracted from a polluted hydrocarbon phase using an aqueous phase containing a complexing agent, iron metalloporphyrins; the aqueous phase is then contacted with a waste hydrocarbon phase and the complexing agent is oxidized, releasing only complexed pollutants into the waste hydrocarbon phase. This cycle is repeated to extract more pollutants from the contaminated phase and concentrate them in the waste phase. Jemaa et al. (1991a) made an analysis of the removal of organosulfur and nitrogen compounds from one phase and concentrating them in another phase using an equilibrium stage process. Their analysis focused on three cases. The first case was where the contaminated phase was continuously contacted with a fresh aqueous layer (no 
concentration of the pollutants). In other cases, the pollutants were extracted and concentrated in a waste organic phase by contact with one or two aqueous phases. The expression of the concentration in different phases (contaminated organic, waste organic, and aqueous) was derived for any stage of the process. Recently, Jemaa et al. (1991b) described a procedure to determine the equilibrium constants for the solute binding and determine whether the complexing agent exits as a monomer or dimer. In a most recent work, Jemaa et al. (1991c) combined mass and energy balances to determine the amount of solute transferred from a feed phase to a receiving phase using a graphical method.

In the analysis we present here, we combine ion exchange and electrochemically reversed complexation to remove heterocyclic organic compounds from an organic phase.

\section{PROCESS DESCRIPTION}

Koval et al. (1988) suggested a cyclical, electrochemical process for the removal of organosulfur and nitrogen compounds from a contaminated organic phase and subsequent concentration to a second waste organic phase. Their process involves extraction of the pollutants into an aqueous phase containing a redox active complexing agent and subsequent electrochemical conversion of the complexing agent to a form with low affinity for the pollutant (oxidation). After release of the organosulfur and nitrogen compounds into the waste organic phase, the binding form of the complexing agent was regenerated electrochemically (reduction). Recently, Jemaa et al. (1991a) described a cyclical electrochemical process for the removal of solutes from one phase and their concentration in a second phase. Solutes are extracted by binding to a complexing agent present in the contacting phase and released to a receiving phase by converting the complexing agent electrochemically to a form with low affinity.

However, there are several aspects of their mechanism that may limit its general applicability. The first and most important limitation involves solubility requirements. For example, the aqueous and hydrocarbon phases must be immiscible in order for the phase to be easily separated. This becomes an imporant consideration when a pollutant, which is very soluble 
in the hydrocarbon phase, has low solubility in the aqueous phase. This pollutant must have minimal solubilify so that it does not stay in aqueous phase. Also, the electroactive carrier cannot be soluble in the hydrocarbon phase since it would eventually be depleted fro. a the system. These solubility requirements are attainable but less stringent requirements would be desirable. In addition, the carrier must have the capability of binding the pollutant and undergoing facile oxidation and reduction at the electrode.

A possible solution to these potential problems is to adsorb the electroastive carrier into beads composed of an ion exchange polymer and to use an electron transfer mediator to modulate its oxidation state. The indirect electrolysis extraction process would operate in the cycle shown in Figure 1. In step 1, pollutant [N-R] will be absorbed into the beads which contains the active form of the complexing agent [Fe(II)P]. When the absorption is complete, the bead will be removed and put into the other phase (step 2) where the pollutant [N-R] will be released by oxidizing the complex $[\mathrm{Fe}(\Pi) \mathrm{P}(\mathrm{N}-\mathrm{R})]$ with a chemical mediator [Mox]. In step 3, the complexing agent [Fe(III)] is regenerated by using another chemical mediator [Mred].

There is still a solubility requirement since the aqueous phase in the beads and the organic phase are immiscible, but in general, one could use a single liquid phase if it wets the bead. Thus, this mechanism simplifies the solubility requirements since immiscible phases are not required. Also, the complexing agent remains within the ion exchange beads which are easily separated from bulk liquid phases. Furthermore, the complexing agent can be selected solely for its complexation properties because the heterogeneous electro-chemistry only involves the mediator. The complexing agent also has to be ionizable so it will exchange into the polymer.

\section{MATHEMATICAL ANALYSIS}

\section{FIRST STEP}

The polymer beads containing the active form of the complexing agent [Fe(II)P] are contacted with the contaminated hydrocarbon phase. The heterocyclic organic compounds (R-S and 
R-N pollutants) would be absorbed within the beads as the complex [Fe(II)P(RS or RN)]. After equilibrium is established, the beads can be removed by filtration. The reaction is;

$$
\mathrm{Fe}(\mathrm{II}) \mathrm{P}+\mathrm{R}-\mathrm{N} \text { or } \mathrm{R}-\mathrm{S} \Leftrightarrow \mathrm{Fe}(\mathrm{II}) \mathrm{P}(\mathrm{RN}) \text { or } \mathrm{Fe}(\mathrm{II}) \mathrm{P}(\mathrm{RS})
$$

Figure 2 shows the system.

Bunge and Noble (1984) have previously modeled a similar system for emulsion liquid membranes. In their model, the solute reacted with a reagent in the internal phase and was captured. The reaction was reversible and the diffusional path length varied with time. There was no back diffusion out of the membrane. This model is used as the basis for the analysis below.

We can assume that pollutant and complexing agent are insoluble in the internal phase (the phase inside the bead). Neglecting activity effects, we assume mass action correctly relates the concentrations of complexing agent, pollutant, and complex in the internal phase:

$$
\mathrm{K}=\frac{\mathrm{CF}_{\mathrm{i}}}{\mathrm{C}_{\mathrm{P} i 1} \mathrm{C}_{\mathrm{i}}}
$$

where $\mathrm{CPi}_{\mathrm{i}}$ is the internal phase concentration of pollutant in step $1, \mathrm{C}_{\mathrm{i}}$ is the complexing agent concentration in the internal phase, $\mathrm{C}_{\mathrm{Fi}_{\mathrm{i}}}$ is the complex concentration in the internal phase.

Complexing agent conservation and reaction stoichiometry require that

$$
\mathrm{C}_{\mathrm{io}}=\mathrm{C}_{\mathrm{i}}+\mathrm{C}_{\mathrm{Fi}}
$$

where $\mathrm{C}_{\mathrm{C} i o}$ denotes the original concentration of complexing agent in the internal phase. Combining equations ( 1 ) and (2) yields

$$
\mathrm{C}_{\mathrm{Fi}}=\frac{\mathrm{K} \mathrm{C}_{\mathrm{Pi}_{1}} \mathrm{C}_{\mathrm{Cio}_{\mathrm{o}}}}{1+\mathrm{K} \mathrm{C}_{\mathrm{Pi}_{\mathrm{i}}}}
$$

The equations describing pollutant concentration in the bulk phase, $\mathrm{C}_{\mathrm{Pb}_{1}}$, and in the internal phase. $\mathrm{CP}_{\mathrm{il}}$,are:

\section{Bulk Phase:}

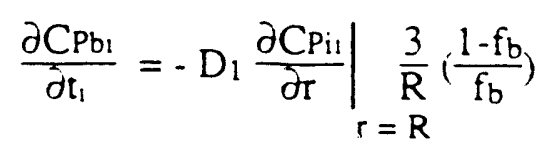




\section{Internal Phase:}

$$
\begin{array}{lll}
\frac{\partial C_{P_{i}}}{\partial t_{1}}=\frac{D_{1}}{r^{2}} \frac{\partial}{\partial r}\left(\frac{r^{2} \partial C_{P_{i 1}}}{\partial r}\right)-\frac{\partial C_{F_{i}}}{\partial t_{1}} & \\
t_{1}=0 & C_{P_{i 1}=0} & (0 \leq r<R) \\
r=R & C_{P_{i 1}}=K_{P b i} C_{P_{1}} & \left(t_{1} \geq 0\right) \\
r=0 & \frac{\partial C_{P_{i 1}}}{\partial r}=0 & \text { (for all } \left.t_{1}\right)
\end{array}
$$

where $\mathrm{KPbi}_{\mathrm{i}}$ is the distribution coefficient between internal and buik phase for the pollutant, $\mathrm{D}_{1}$ is the diffusion coefficient of pollutant in step $1, R$ is the radius of a bead, $f_{b}$ is the bulk phase fraction of the total volume.

The time derivative on the right side of equation (5) accounts for concentration changes of the pollutant in the internal phase by complexation with the complexing agent. Taking the derivative of equation (3) with respect to time yields:

$$
\frac{\partial C_{F_{i}}}{\partial t_{1}}=\frac{K C_{C_{i o}}}{\left(1+K C_{P_{i 1}}\right)^{2}} \frac{\partial C_{P_{i 1}}}{\partial t_{1}}
$$

Substituting equation (9) into equation (5) yields a differential equation in terms of the internal phase pollutant concentration only.

Using the following definitions, we cast these equations into dimensionless form.

$$
\begin{aligned}
& \Phi_{P_{b 1}}=\frac{C_{P_{1}}}{C_{P b_{10}}} ; \quad \Phi_{P_{i 1}}=\frac{C_{P_{i 1}}}{K_{P_{1} C_{P_{10}}}} ; \quad \quad \quad \quad=\frac{r}{R} ; \quad \tau_{1}=\frac{D_{1 t_{1}}}{R^{2}} ; \\
& \sigma_{1}=\frac{\left(1-f_{b}\right)}{f_{b}} K_{P b i} ; \quad \sigma_{2}=K C_{C i o} ; \quad \sigma_{3}=K K_{P b i} C_{P b i o ~}
\end{aligned}
$$

where $\Phi_{\mathrm{Pb}_{\mathrm{i}}}$ is the dimensionless bulk phase pollutant concentration in step $1, \Phi_{\mathrm{P}_{\mathrm{i}}}$ is the dimensionless intermal phase pollutant concentration in step $1, \eta$ is the dimensionless position, $\tau_{1}$ is the dimensionless time in step 1.

In dimensionless form, equations (4) - (8) becomes: 


$$
\begin{aligned}
& \frac{d \Phi P_{b_{1}}}{d \tau_{1}}=-3 \sigma_{1} \frac{\partial \Phi_{P_{i 1}}}{\partial \eta} \\
& \tau_{1}=0 \quad \Phi_{\mathrm{Pb}_{1}}=1.0 \\
& \frac{\partial \Phi_{\mathrm{P}_{i 1}}}{\partial \tau_{1}}=\frac{1}{\eta^{2}} \frac{\partial}{\partial \eta}\left(\eta^{2} \frac{\partial \Phi_{\mathrm{Pi}_{1}}}{\partial \eta}\right)\left\{\frac{1}{\left[1+\sigma_{2} /\left(1+\sigma_{3} \Phi_{\mathrm{Pi}_{1}}\right)^{2}\right]}\right\} \\
& \tau_{1}=0 \quad \Phi_{P_{i 1}}=0 \quad(0 \leq \eta<1) \\
& \eta=1 \quad \Phi_{\mathrm{Pi}_{1}}=\Phi_{\mathrm{Pb}_{1}} \quad\left(\tau_{1} \geq 0\right) \\
& \eta=0 \quad \frac{\partial \Phi_{P_{i 1}}}{\partial \eta}=0 \quad\left(\text { all } \tau_{1}\right)
\end{aligned}
$$

The physical significance of the dimensionless groups defined in equation (11) is worth considering. Consisting of volume fractions and partition coefficients, $\sigma_{1}$ measures the internal phase capacity for a pollutant relative to the bulk phase capacity, $\sigma_{2}$ represents the original complexing agent concentration and $\sigma_{3}$ represents the initial bulk phase pollutant concentration.

Equation (14) is nonlinear and does not have an analytical solution. Equations (12) and (14) were solved simultaneously for relevant conditions using an IMSL routine [Inter. Math. Statis. Lib.] called MOLCH/DMOLCH. The routine uses the method of lines with cubic Hermite polynomials. The results are shown on Figures 3 and 4 . As we see from the graphs, the amount of pollutant removed is strictly dependant on $\sigma_{3}$ which changes with the distribution coefficient, and $\sigma_{1}$ which changes with the number of beads. By keeping the bulk phase volume constant, increasing the $\left(1-f_{b}\right) / f_{b}$ ratio means increasing the number of the beads in the bulk phase. With higher $\sigma_{2} / \sigma_{3}$ ratio we get almost $99 \%$ removal of the pollutant. Also higher values of $\sigma_{3}$ provide larger removal in less time.

We can also find the final equilibrium values by writing an overall material balance for the pollutant at equilibrium: 


$$
\Phi^{* 2} \mathrm{~Pb}:+\Phi^{*} \mathrm{~Pb}_{1}\left\{\frac{1+\sigma_{1}+\sigma_{1} \sigma_{2}-\sigma_{3}}{\sigma_{3}+\sigma_{1} \sigma_{3}}\right\}-\left\{\frac{1}{\sigma_{3}+\sigma_{1} \sigma_{3}}\right\}=0
$$

where $\Phi^{\prime \prime} \mathrm{Pb}$ is the dimensionless bulk phase pollutant concentration at equilibrium by defining

$$
\mathrm{m}=\frac{1+\sigma_{1}+\sigma_{1} \sigma_{2}-\sigma_{3}}{2\left(\sigma_{3}+\sigma_{1} \sigma_{3}\right)} ; \quad \mathrm{z}=\frac{1}{\sigma_{3}+\sigma_{1} \sigma_{3}}
$$

equation (18) becomes

$$
\Phi^{* 2} \mathrm{~Pb}_{1}+2 \mathrm{~m} \Phi^{*} \mathrm{~Pb}_{1}-\mathrm{z}=0
$$

the positive root of equation (20) is

$$
\Phi_{\mathrm{Pb}_{1}}^{*}=-m+\sqrt{m^{2}+z}
$$

Thus, one can compute the final equilibrium pollutant concentration by using equation (21).

\section{SECOND STEP:}

The pollutants are released into a waste phase and the beads are regenerated in an electrochemical reactor. As it is seen in Figure 5, the mediator [M] is oxidized at the electrodes and dissolves inte the beads where it oxidizes the complex to the inactive form [Fe(III)P(RS or RN)] which has a low affinity for R-S and R-N. The reverse of the complexation reaction takes place and the pollutants, being relatively insoluble in the hydrated beads and aqueous electrolytic phase, diffuse to the waste hydrocarbon phase.

$$
\mathrm{Fe}(\mathrm{II}) \mathrm{P}(\mathrm{RN}) \text { or } \mathrm{Fe}(\mathrm{II}) \mathrm{P}(\mathrm{RS})-\mathrm{e}^{-} \Leftrightarrow \mathrm{Fe}(\mathrm{III}) \mathrm{P}+\mathrm{R}-\mathrm{N} \text { or } \mathrm{R}-\mathrm{S}
$$

Equations describing step two will be similar to the equations which are defined in step one except that now we have an irreversible reaction. We also have countercurrent diffusion; for each mole of mediator that enters the beads. one mole of poilutant exits since each complexing agent binds one pollutant. Since the reaction is very fast, there will be a reaction front. Thus, equations which describe the mediator diffusing in and pollutant diffusing out are;

\section{Mediator equations:}

Bulk phase

$$
\frac{\partial C_{M b 2}}{\partial t_{2}}=-\left.D_{2} \frac{\partial C M_{i 2}}{\partial r}\right|_{r=R} \frac{3}{R}\left(\frac{1-f_{b}}{f_{b}}\right)
$$




$$
\mathrm{t}_{2}=0 \quad \mathrm{CMb}_{2}=\mathrm{CMb}_{20}
$$

Internal phase

$$
\begin{array}{lll} 
& \frac{\partial C_{M i 2}}{\partial t_{2}}=\frac{D_{2}}{r^{2}} \frac{\partial}{\partial r}\left(\frac{r^{2} \partial C_{M i 2}}{\partial r}\right) & \\
t_{2}=0 & C_{M i 2}=0 & \left(R_{f}\left(t_{2}\right) \leq r \leq R\right) \\
r=R & C_{M i 2}=K_{M b i} C_{M b 2} & \left(t_{2}>0\right) \\
r=R f\left(t_{2}\right) & C_{M i 2}=0 & \left(t_{2}>0\right)
\end{array}
$$

Reaction front

$$
\begin{array}{ll}
-C_{F_{0}} \frac{d R_{f}}{d t_{2}}=\left.D_{2} \frac{\partial C_{M i 2}}{\partial r}\right|_{r=R_{f}\left(t_{2}\right)} \\
t_{2}=0 & R_{f}=R
\end{array}
$$

where $\mathrm{C}_{\mathrm{Mb} \text { o }}$ is the initial bulk phase mediator concentration in step 2, $\mathrm{C}_{\mathrm{Mb}}$ is the bulk phase mediator concentration in step 2, $\mathrm{C}_{\mathrm{Mi}}$ is the internal phase mediator concentration in step 2, $\mathrm{K}_{\mathrm{Mb}}$ is the distribution coefficient between internal and bulk phase for the mediator, $R_{f}$ is the reaction front position, $D_{2}$ is the diffusion coefficient of mediator for step 2, and $C_{F o}$ is the initial concentration of complex.

The equations which describe the pollutant diffusing out are;

\section{Pollutant equations:}

Bulk phase

$$
\begin{aligned}
& \frac{\partial C \mathrm{~Pb}_{2}}{\partial \mathrm{t}_{2}}=\left.\mathrm{D}_{2} \frac{\partial C \mathrm{Pi}_{2}}{\partial r}\right|_{\substack{\mathrm{R}=\mathrm{R} \\
\mathrm{r}}} ^{\frac{3}{\mathrm{f}_{\mathrm{b}}}}\left(\frac{1-\mathrm{f}_{\mathrm{b}}}{\mathrm{t}_{2}=0} \quad \mathrm{CPb}_{20}=0.0\right.
\end{aligned}
$$

Internal phase

$$
\frac{\partial C_{P_{i 2}}}{\partial t_{2}}=\frac{D_{2}}{r^{2}} \frac{\partial}{\partial r}\left(\frac{r^{2} \partial C_{P_{i 2}}}{\partial r}\right)
$$




$$
\begin{aligned}
& \mathrm{t}_{2}=0 \quad \mathrm{CPi}_{2}=\mathrm{CPi}_{\mathrm{i} 2 \mathrm{O}} \quad\left(\mathrm{R}_{\mathrm{f}}\left(\mathrm{t}_{2}\right) \leq \mathrm{r} \leq \mathrm{R}\right) \\
& \mathrm{r}=\mathrm{R} \quad \mathrm{CP}_{\mathrm{P}_{22}}=\mathrm{K}_{\mathrm{Mbi}} \mathrm{C}_{\mathrm{Pb}_{2}} \quad\left(\mathrm{t}_{2}>0\right) \\
& \mathrm{r}=\mathrm{R}_{\mathrm{f}}\left(\mathrm{t}_{2}\right) \quad \mathrm{C}_{\mathrm{Pi}_{\mathrm{i}}}=\mathrm{C}_{\mathrm{P}_{120}} \quad\left(\mathrm{t}_{2}>0\right)
\end{aligned}
$$

Reaction front

$$
\begin{array}{ll}
C_{F_{0}} \frac{d R_{f}}{d t_{2}}=\left.D_{2} \frac{\partial C P_{i}}{\partial r}\right|_{r=R_{f}\left(t_{2}\right)} & R_{f}=R
\end{array}
$$

where $\mathrm{CP}_{\mathrm{i} 2}$ is the internal phase pollutant concentration in step 2, $\mathrm{CPb}_{20}$ is the initial bulk phase pollutant concentration in step 2, and $\mathrm{CPb}_{2}$ is the bulk phase pollutant concentration in step 2 . Using the following definitions, we cast equations 22-37 into dimensionless form.

$$
\begin{aligned}
& \Phi_{M_{b 2}}=\frac{C_{M b 2}}{C_{M b_{02}}} ; \quad \Phi_{M i 2}=\frac{C_{M i 2}}{K_{M} b_{1} C_{M b 20}} ; \quad \eta=\frac{r}{R}: \quad \chi=\frac{R_{f}}{R} ; \quad \sigma_{4}=\frac{\left(1-\hat{f}_{b}\right)}{f_{b}} K_{M b i} \\
& \Phi_{\mathrm{Pb}_{2}}=\frac{\mathrm{CPb}_{\mathrm{P} 2}}{\mathrm{CPbo}_{\mathrm{P}}}: \quad \Phi_{\mathrm{Piz}_{2}}=\frac{\mathrm{CP}_{\mathrm{Pi}}}{\mathrm{K}_{\mathrm{Mbi} \mathrm{Pb}_{20}}} ; \tau_{2}=\frac{\mathrm{D}_{2 \mathrm{t}_{2}}}{\mathrm{R}^{2}}: \quad \varepsilon=\frac{\mathrm{K}_{\mathrm{Mbi}} \mathrm{C}_{\mathrm{Mb} 20}}{\mathrm{C}_{\mathrm{Fo}}}
\end{aligned}
$$

Mediator equations:

Bulk phase:

$$
\begin{aligned}
& \frac{\mathrm{d} \Phi_{\mathrm{Mb} 2}}{\mathrm{~d} \tau_{2}}=3 \sigma_{4} \frac{\partial \Phi_{\mathrm{Mi}}}{\partial \eta} \\
& \eta=1 \\
& \tau_{2}=0 \quad \Phi_{M b_{2}}=1.0
\end{aligned}
$$

Internal phase:

$$
\begin{array}{lll}
\frac{\partial \Phi_{M i 2}}{\partial \tau_{2}}=\frac{1}{\eta^{2}} \frac{\partial}{\partial \eta}\left(\eta^{2} \frac{\partial \Phi_{M i 2}}{\partial \eta}\right) & \\
\tau_{2}=0 & \Phi_{M i 2}=0 & (\chi \leq \eta \leq 1) \\
\eta=1 & \Phi_{M i 2}=\Phi_{M b 2} & \left(\tau_{2}>0\right) \\
\eta=\chi & \Phi_{M i 2}=0 & \left(\tau_{2}>0\right)
\end{array}
$$


Reaction front;

$$
\begin{aligned}
& \frac{\mathrm{d} \chi}{\mathrm{d} \tau_{2}}=-\varepsilon \frac{\Phi_{\mathrm{Mi} 2}}{\mathrm{~d} \eta} \mid \\
& \eta=u(\tau) \\
& \tau_{2}=0 \quad \chi=1.0
\end{aligned}
$$

Pollutant equations:

Bulk phase:

$$
\begin{array}{ll}
\frac{\mathrm{d} \Phi_{\mathrm{P}_{\mathrm{b}}}}{\mathrm{d} \tau_{2}}=\left.3 \sigma_{4} \frac{\partial \Phi_{\mathrm{P}_{\mathrm{i}} 2}}{\partial \eta}\right|_{\eta=1} \\
\tau_{2}=0 & \Phi_{\mathrm{Pb}_{2}}=0.0
\end{array}
$$

Internal phase;

$$
\begin{array}{lll}
\frac{\partial \Phi_{\mathrm{Pi} 2}}{\partial \tau_{2}}=\frac{1}{\eta^{2}} \frac{\partial}{\partial \eta}\left(\eta^{2} \frac{\partial \Phi_{\mathrm{Pi}_{2}}}{\partial \eta}\right) & \\
\tau_{2}=0 & \Phi_{\mathrm{Pi}_{2}}=1.0 & (0 \leq \eta \leq 1) \\
\eta=1 & \Phi_{\mathrm{Pi}_{2}}=\Phi_{\mathrm{Pb} 2} & \left(\tau_{2}>0\right) \\
\eta=\chi & \Phi_{\mathrm{Pi}_{2}}=1.0 & \left(\tau_{2}>0\right)
\end{array}
$$

Reaction front:

$$
\begin{aligned}
& \frac{\mathrm{d} \chi}{\mathrm{d} \tau_{2}}=\left.\varepsilon \frac{\Phi \mathrm{Pi}_{2}}{\mathrm{~d} \eta}\right|_{\eta=\chi(\tau)} \\
& \tau_{2}=0 \quad \chi=1.0
\end{aligned}
$$

Solutions of equations $40-47$ is already given by Ho et al. (1982) by using a perturbation method. Equations 48-55 are very similar to the mediator equations except for the boundary conditions. By using a perturbation solution we also solved them analytically. By detining the following transformations;

$$
\kappa=\eta \Phi_{M i 2}
$$




$$
\delta=\frac{(1-\eta)}{(1-\chi)}
$$

the zero order solution of the mediator equations are;

$$
\begin{aligned}
& \kappa^{\circ}=\frac{E}{3}\left(\chi^{3}-B^{3}\right)(1-\delta) \\
& \Phi_{M b_{2}}^{\circ}=\frac{E}{3}\left(\chi^{3}-B^{3}\right) \\
& \tau^{\circ}==\frac{1}{E \varepsilon}\left\{\left(1+\frac{1}{2 B}\right) \ln \frac{\left(\chi^{3}-B^{3}\right)}{\left(1-B^{3}\right)}-\frac{3}{2 B} \ln \frac{(\chi-B)}{(1-B)}\right\} \\
& \quad-\frac{\sqrt{3}}{E B \varepsilon}\left\{\tan ^{-1} \frac{(2 \chi+B)}{\sqrt{3} B}-\tan ^{-1} \frac{(2+B)}{\sqrt{3} B}\right\}
\end{aligned}
$$

where

$$
\begin{aligned}
& B=\left(1-\frac{3}{E}\right)^{1 / 3} \\
& E=3\left(\frac{C_{F_{0}} V_{i}}{C_{M b_{20}} V_{b}}\right)
\end{aligned}
$$

Also by defining;

$$
\omega=\eta \Phi_{P_{i 2}}
$$

the zero order solution of the pollutant equations are;

$$
\begin{aligned}
& \omega^{\circ}=\delta \chi+\Phi_{\mathrm{Pb}_{2}}(1-\delta) \\
& \Phi_{\mathrm{Pb} 2}^{\circ}=\frac{E}{3}\left(1-\chi^{3}\right)
\end{aligned}
$$

The detailed information of above procedures is given by Ho et al.(1982) and Ozekin ei al.(1991).

We assumed that the position of the reaction front at a given time is the same for the mediator and the pollutant. Thus, $\tau^{\circ}{ }_{2}$ defines time for both pollutant and mediator. Figure 6 shows how bulk phase pollutant concentration is changing with time. As we see from the graph, for the given time we can concentrate more pollutant with the less bulk phase volume. On the other hand, Figure 7 shows the internal phase pollutant concentration at a given reaction front position. On the 
left side of the reaction front position the dimensionless pollutant concentration is one since the mediator did notreact with the pollutant in that region yet.

\section{THIRD STEP:}

When the second step in the process is completed, the waste hydrocarbon phase is removed and the mediator is reduced. The reduced form of the mediator diffuses into the beads and regenerates the active form of the complexing agent (Figure 8 ). The beads can be removed from the reactor and are ready to be contacted with more contaminated hydrocarbon phase. The reactions describing this step are;

$$
\begin{aligned}
& \mathrm{M} \rightarrow \mathrm{M}^{-}+\mathrm{e}^{-} \\
& \mathrm{Fe}(\mathrm{II}) \mathrm{P}+\mathrm{M}^{-} \rightarrow \mathrm{Fe}(\mathrm{II}) \mathrm{P}+\mathrm{M}
\end{aligned}
$$

The reaction is instantaneous and irreversible. The mediator, which diffuses into the particle, is immediately converted by the reaction. Thus, a sharp boundary, or a reaction front at which reaction takes place exists. The reaction front forms the inner region containing the reduced form of the complexing agent and the outer region which contains the oxidized form of the complexing agent .

This step is also similar to step one. The only differences are, instead of havirg a reversible reaction, we have an irreversible reaction and there is a reaction front position which causes a sharp boundary. We can simplify equations (5-8) and equation (4) which describes the bulk phase concentration will remain the same. Our new equations;

Bulk fhase:

$$
\begin{array}{ll}
\frac{\partial C M_{3}}{\partial t_{3}}=-\left.D_{3} \frac{\partial C \cdot M i 3}{\partial r}\right|_{\substack{R=R \\
:=R}} ^{\frac{3}{R}\left(\frac{1-f_{b}}{f_{b}}\right)} & \\
t_{3}=0 & C_{M b_{3}}=C_{M} b_{30}
\end{array}
$$


Internal phase:

$$
\begin{array}{lll}
\frac{\partial C_{M i 3}}{\partial t_{3}}=\frac{D_{3}}{2} \frac{\partial}{\partial r}\left(\frac{\partial \partial C_{M i 3}}{\partial r}\right) & \\
t_{3}=0 & C_{M i 3}=0 & \left(R_{f}\left(t_{3}\right) \leq r \leq R\right) \\
r=R & C_{M i 3}=K_{M b i} C_{M b_{3}} & \left(t_{3}>0\right) \\
r=R_{f}\left(t_{3}\right) & C_{M i 3}=0 & \left(t_{3}>0\right)
\end{array}
$$

Reaction front:

$$
\begin{array}{ll}
-C_{C_{i o}} \frac{d R_{f}}{d t_{3}}=\left.D_{3} \frac{\partial C_{M i 3}}{\partial r}\right|_{r=R f\left(t_{3}\right)} \\
t_{3}=0 & R_{f}=R
\end{array}
$$

where CMbso is the initial bulk phase mediator concentration in step 3, CMbs is the bulk phase mediator concentration in step 3, C.Mis is the internal phase mediator concentration in step 3 , and $D_{3}$ is the diffusion coefficient of the mediator in step 3.

Using the following definitions, we cast these equations into dimensionless form.

$$
D_{M b 3}=\frac{C_{M b 3}}{C_{M b 30}} ; \Phi_{M i 3}=\frac{C_{M i 3}}{K_{M b i} C_{M b 30}} ; \tau_{3}=\frac{D_{3 t_{3}}}{R^{2}} ; \quad \rho=\frac{K_{M b i} C_{M b 30}}{C_{C i o}} ;
$$

In dimensionless form, equations (66-73) become:

Bulk phase;

$$
\begin{aligned}
& \frac{d \Phi_{M b_{3}}}{d \tau_{3}}=-\left.3 \sigma_{4} \frac{\partial \Phi_{M i 3}}{\partial \eta}\right|_{\eta=1} \\
& \tau_{3}=0 \quad \Phi_{M b_{3}}=1.0
\end{aligned}
$$

Internal phase;

$$
\frac{\partial \Phi_{M i 3}}{\partial \tau_{3}}=\frac{1}{\eta^{2}} \frac{\partial}{\partial \eta_{1}}\left(\eta^{2} \frac{\partial \Phi_{M i 3}}{\partial \eta}\right)
$$




$$
\begin{array}{lll}
\tau_{3}=0 & \Phi_{\mathrm{Mi} 3}=0 & (0 \leq \eta \leq 1) \\
\eta=1 & \Phi_{\mathrm{Mi3}}=\Phi_{\mathrm{Mb} 3} & \left(\tau_{3}>0\right) \\
\eta=\chi & \Phi_{\mathrm{Mi}_{\mathrm{i}}}=0 & \left(\tau_{3}>0\right)
\end{array}
$$

Reaction front;

$$
\begin{aligned}
& \frac{\mathrm{d} \chi}{\mathrm{d} \tau_{3}}=-\rho \frac{\Phi_{\mathrm{Mi3}}}{\mathrm{d} \eta} \\
& \eta=\chi(\tau) \\
& \tau_{3}=0 \quad \chi=1.0
\end{aligned}
$$

Equations (75 - 82) have an analytical solution. Ho et al.(1982) solved very similar equations for liquid membranes by using a perturbation method. By defining the following transformations;

$$
\begin{aligned}
& \psi=\eta \Phi_{\mathrm{Mi} 3} \\
& \delta=\frac{(1-\eta)}{(1-\chi)}
\end{aligned}
$$

the zero order solutions of above equations are:

$$
\begin{aligned}
\Psi^{\circ} & =\frac{L}{3}\left(\chi^{3}-P^{3}\right)(1-\delta) \\
\Phi^{\circ} M_{b 3} & =\frac{L}{3}\left(\chi^{3}-P^{3}\right) \\
\tau_{3}^{\circ}= & \frac{1}{L \rho}\left\{\left(1+\frac{1}{2 P}\right) \ln \frac{\left(\chi^{3}-P^{3}\right)}{\left(1-P^{3}\right)}-\frac{3}{2 P} \ln \frac{(\chi-P)}{(1-P)}\right\} \\
& -\frac{\sqrt{3}}{L P \rho}\left\{\tan ^{-1} \frac{(2 \chi+P)}{\sqrt{3} P}-\tan ^{-1} \frac{(2+P)}{\sqrt{3} P}\right\}
\end{aligned}
$$


where

$$
\begin{aligned}
& P=\left(1-\frac{3}{L}\right)^{1 / 3} \\
& L=3\left(\frac{C_{\text {Cio }} V_{i}}{C_{M b_{30}} V_{b}}\right)
\end{aligned}
$$

The results are shown on Figure 9. By increasing the number of beads, the time to reach a given reaction front position is increasing. By increasing the number of the beads, we also increase the total amount of the complexing agent available. As we see from the dimensionless time definition, the real time is effected by the diffusion coefficient and the bead radius. At this point one can argue that for the same bead radius, using a gas mediator will give less real time than using a chemical mediator because the gas mediator diffusion coefficient is much faster than a chemical mediator's. For example, a chemical mediators, Europium, diffusion coefficient in water is $2.26 \times 10^{-7} \mathrm{~cm}^{2} / \mathrm{sec}$ (Ozekin, 1991) and a gas mediator's, Hydrogen, diffusion coefficient in water is $4.5 \times 10^{-5} \mathrm{~cm}^{2} / \mathrm{sec}$ (Cussler, 1984). Thus, choosing Hydrogen over Europium as a mediator will give almost 200 times faster diffusion of the mediator. 


\section{CONCLUSION}

The removal of organosulfur and nitrogen compounds from an organic phase using an ion exchange polymer containing an electroactive chemical complexing agent consists of three main steps. In the first step, the pollutants were extracted from an organic phase. The solution of the equ. .ions which describe the internal and bulk phase pollutant concentration shows that $99 \%$ extraction is possible with a large value of $\sigma_{3}$ and a high number of beads. In the second step, the pollutants were concentrated into a waste organic phase by oxidizing the carrier with a gas mediator. A moving boundary problem was solved by using a perturbation solution. With the results we are able to find the time necessary to concentrate almost all the pollutant into the waste phase and for the given time we san concentrate more pollutant with less bulk phase volume. We also have an expression to see how the bulk phase pollutant and mediator concentrations are changing with time. The third step is the reduction of the complexing agent with a chemical mediator. With the equations that we derived we can estimate the necessary time for the reduction of the complexing agent. Equations were solved analytically by using a perturbation solution. 


\section{ACKNOWLEDGMENT}

This work is supported by U.S. Department of Energy, Pittsburgh Energy Technology Center (Grant no: DE-FG22-88PC88916). The authors gratefully acknowledge its support. 


\section{NOTATION}

B Constant, Eq. 61

$\mathrm{CC}_{\mathrm{i}}$ Complexing agent concentration in the internal phase

CCio Initial complexing agent concentration in the internal phase

$\mathrm{C}_{\mathrm{Fi}}$ Complex concentration in the internal phase

$\mathrm{C}_{\mathrm{Fo}}$ Initial concentration of complex in the bead

$\mathrm{C}_{\mathrm{Mi}}$ Internal phase mediator concentration in step two

CMbəo Initial bulk phase mediator concentration in step two

C.1b3o Initial bulk phase mediator concentration in step three

CMbz Bulk phase mediator concentration in step two

CMbs Bulk phase mediator concentration in step three

$\mathrm{C}_{\mathrm{M}}$ Internal phase mediator concentration in step three

C.Mi: Internal phase mediator concentration in step two

$\mathrm{CPb}$ : Bulk phase pollutant concentration in step one

CPh:D Initial bulk phase pollutant concentration in step one

CPb: Bulk phase pollutant concentration in step two

C $p_{::} \quad$ Pollutant concentration in the internal phase in step one

$\mathrm{CP}_{12}$ Pollutant concentration in the internal phase in siep two

Di Diffusion coefficient in step one

D: Diffusion coefficient in step two

D3 Diffusion coefficient in step three

E Constant, Eq.62

is Bulk phase fraction of the total volume

K Equilibrium constant

$\mathrm{KPh}$ Distribution coefficient between internal and bulk phase for pollutant

K.Mbi Distriburion coefficient between internal and bulk phase for mediator 
L Constant, Eq.89

m Dimensionless group, Eq.19

M Mediator

P Constant, Eq. 88

r Radial coordinate

R Radius of a bead

$R_{f} \quad$ Reaction front position

i Time

t1 Necessary time to pollutant to diffuse into the beads in step one

t2 Necessary time to elution of pollutant in step two

i3 Necessary time for mediator to diffuse into the beads in step three

z Dimensionless group, Eq.19

o Transformation. Eq.57

$\varepsilon \quad$ Perturbation parameter. Eq.39

$\eta \quad$ Dimensionless position

$\kappa \quad$ Transformation. Eq.56

p Perturbation parameter, Eq.74

$\omega$ Transformation. Eq.63

$\sigma_{1} \quad$ Dimensionless group, Eq.11

02 Dimensionless group, Eq.11

$\sigma_{3}$ Dimensionless group, Eq. 11

$\sigma_{4} \quad$ Dimensionless group, Eq. 38

$\Phi_{\text {Mb2 }}$ Dimensionless bulk phase mediator concentration in step two

$\Phi_{\text {Mbs }}$ Dimensionless bulk phase mediator concentration in step three

$\Phi_{\text {Mi2 }}$ Dimensionless internal phase mediator concentration in step two

$\Phi_{\mathrm{Mis}}$ Dimensionless internal phase mediator concentration in step three 
$\Phi_{\mathrm{Pb} \text { l }}$ Dimensionless bulk phase pollutant concentration in step one

$\Phi^{*} \mathrm{Pht}$ Dimensionless bulk phase pollutant concentration at equilibrium in step one

$\Phi_{\mathrm{Pb}_{2}}$ Dimensionless bulk phase pollutant concentration in step two

$\Phi_{\mathrm{P}_{i}}$ Dimensionless internal phase pollutani concentration in step one

$\Phi_{\mathrm{P}_{\mathrm{i}}} \quad$ Dimensionless internal phase pollutant concentration in step two

$\tau_{1} \quad$ Dimensionless time in step one

$\tau_{2}$ Dimensionless time in step two

23 Dimensionless time in step three

$\chi \quad$ Dimensionless reaction front position

$\psi \quad$ Transformation. Eq.83 


\section{REFERENCES}

1. Adams, G., P.M. Jones and J.R. Millar, "Kinetics of Acid L'ptake by Weak-Base Anion Exchangers," J. Chem. Soc., 2543, (1969 A).

2. Astle, M.J., "Ion Exchangers as Catalysts," in Ion Exchangers in Organics and Biochemistry, C. Calmon and T.R.E. Kressman, eds., New York: Interscience, p. 658 (1975).

3. Blickenstaff, R.A., J.D.Wagner and J.S. Dranoff, "The Kinetics of Ion Exchange Accompanied by Irreversible Reactions. I- Film Diffusion Controlled Neutralization of A Strong Acid Exchanger by Strong Bases," J. Phys. Chem., 71, 1665 (1967a).

4. Blickenstaff, R.A., J.D. Wagner and J.S. Dranoff, "The Kinetics of Ion Exchange Accompanied by Irreversible Reactions. II- Intraparticle Diffusion Controlled Neutralization of A Strong Acid Exchanger by Strong Bases," J. Phys. Chem., 71, 1670 (1967b).

5. Bunge, A.L. and R.D. Noble, "A Diffusion Model for Reversible Consumption in Emulsion Liquid Membranes," J. Mem. Sci., 21, 55 (1984).

6. Cussler, E.L., Diffusion: Mass Transfer in Fluid Systems. Cambridge: Cambridge Press, (1984).

7. Dana, P.R. and T.D.Wheelock, "Kinetics of Moving Boundary Ion Exchange Process," AIChE J., 13, 20 (1974).

8. Davison, J., F.O. Read, F.D.L. Noakes and T.V. Arden. "Ion Exchange for Gold Recovery," Bull. Inst. Mining Met., 651, 247 (1961).

9. Dorfner, K., Ion Exchangers. Michigan: Ann Arbor Science Publ., p.103 (1972).

10. Gans, R., Jahrb.Preuss.Geol. Landesanstalt (Berlin), 26, 179 (1905).

11. Gerstner, F V., "Die Wiederge Winnung von Kupfer in der Kupferfaser-Erzeugung," Z. Electrochem., 57, 221 (1953).

12. Helfferich, F., "Ion Exchange Kinetics, V - Ion Exchange Accompanied by Reactions," J. Phys. Chem., 69, 1178 (1965). 
13. Ho, W.S., H.T. Hatton, E.N. Lightfoot and N.N. Li, "Batch Extraction With Liquid Surfactant Alembranes: A. Diffusion Controlled Model," AIChE J., 28, 662 (1982).

14. Holl,W., "Optical Verification of Ion Exchange Mechanism in Weak Electrolyte Resins," Reac. Polym., 2. 93 (1984).

15. IMSL, International Mathematical Statistical Libraries (IMSL), Inc., 1982, Edition 9.2.

16. Jemaa,N., R.D. Noble, C.A. Koval and J. Yu, "Electrochemically Modulated Equilibrium Stage Processes," Chem. Eng. Sci., 46, 1017 (1991a).

17. Jemaa.N., J. Yu, R.D. Noble, S.M. Drew, D.E. Weciman and C.A. Koval, "Two Methods To Study Aggregation of Complexing Agents Used To Alter Solute Partitioning Between Phases," I\&EC J. (1991b), Submitted for Publication.

18. 'zmaa,N, R.D. Noble and C.A. Koval, "Combined Mass and Energy Balance Analysis of An Electrochemically Modulated Equilibrium Stage Process," Chem. Eng. Sci. (1991c), Submitted for Publication.

19. Koval, C.A., S.M. Drew, T. Spontarelli and R.D. Noble, "Concentration and Removal of Nitrogen and Sulfur Containing Compounds from Organic Liquid Phase Using Electrochemically Reversed Complexation," Sep. Sci. and Tech., 23, 1389 (1988).

20. Nativ, M., S. Goldstein and G.Schmuckler, "Kinetics of Ion Exchange Processes Accompanied by Chemical Reactions," J. Inor. Nuc. Chern., 37, 1951 (1975).

21. Ozekin, K., "Removal of Sulfur and Nitrogen Compounds from an Organic Phase Using Ion Exchange Polymer," Ms Thesis, University of Colorado, Boulder, Co (1991)

22. Ozekin, K. and R.D.Noble, "Solution of A Spherical Shrinking Core Problem With Countercurrent Diffusion by A Perturbation Method: Electrochemically Modulated Complexation in Ion-Exchange Beads,"AIChE J. (1991), Submitted for Publication.

23. Selim, M.S. and R.C. Seagrave, "Solution of Moving Boundary Transport Problem In Finite Media by Integral Transforms. III- The Elution Kinetics of the Copper Ammine Complex from A Cation Exchange Resin," I\&EC Fund., 12, 14 (1973). 
24. Schmuckler, G., "Kinetics of Moving Boundary Ion Exchange Process," Reac. Poly., 2, $103(1984)$.

25. Thompson, H.S., "On Subsoil-Plnughing," Agric. Soc. Journ., II. 26 (1841).

26. Warner.R.E., A.M. Kennedy and B.A. Bolto, "Kinetics of Neutralization of Weak Electrolyte Ion Exchange Resins," J. Macromol. Sci.-Chem., A4, 1125 (1970). 


\section{FIGURE CAPTIONS}

Figure 1- One stage of an indirect electrolysis extraction process

Figure 2- Removal of pollutant from waste phase

Figure 3- Fraction removed with time

Figure 4- Fraction removed for different number of beads

Figure 5- Diffusion of pollutant from beads by using mediator

Figure 6- Bulk phase pollutant concentration versus time for different bulk phase volumes

Figure 7-Change in the internal phase pollutant concentration with time

Figure 8- Reduction of complexing agent

Figure 9-Reaction front versus time for different number of the beads 


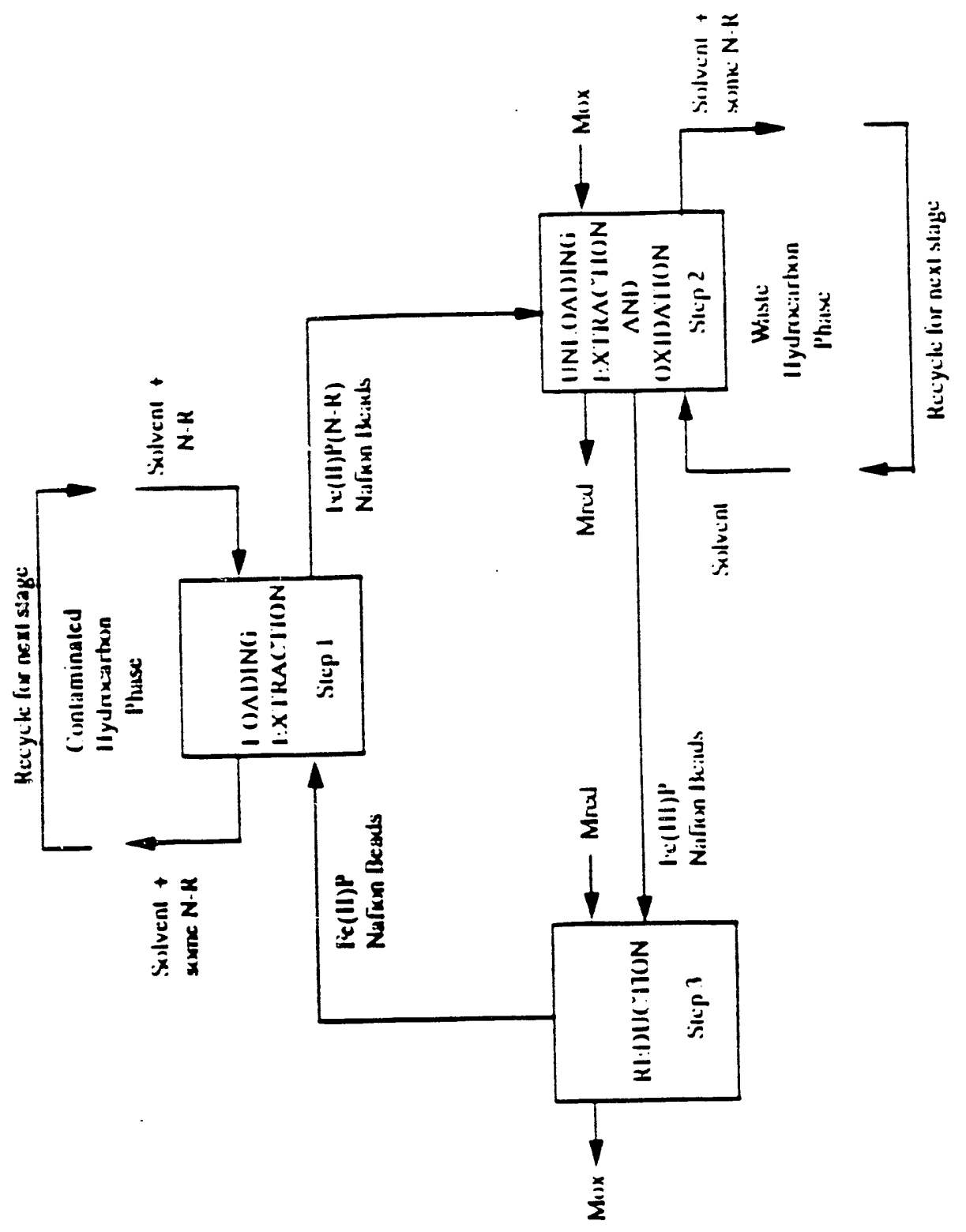

Figure 1 . 


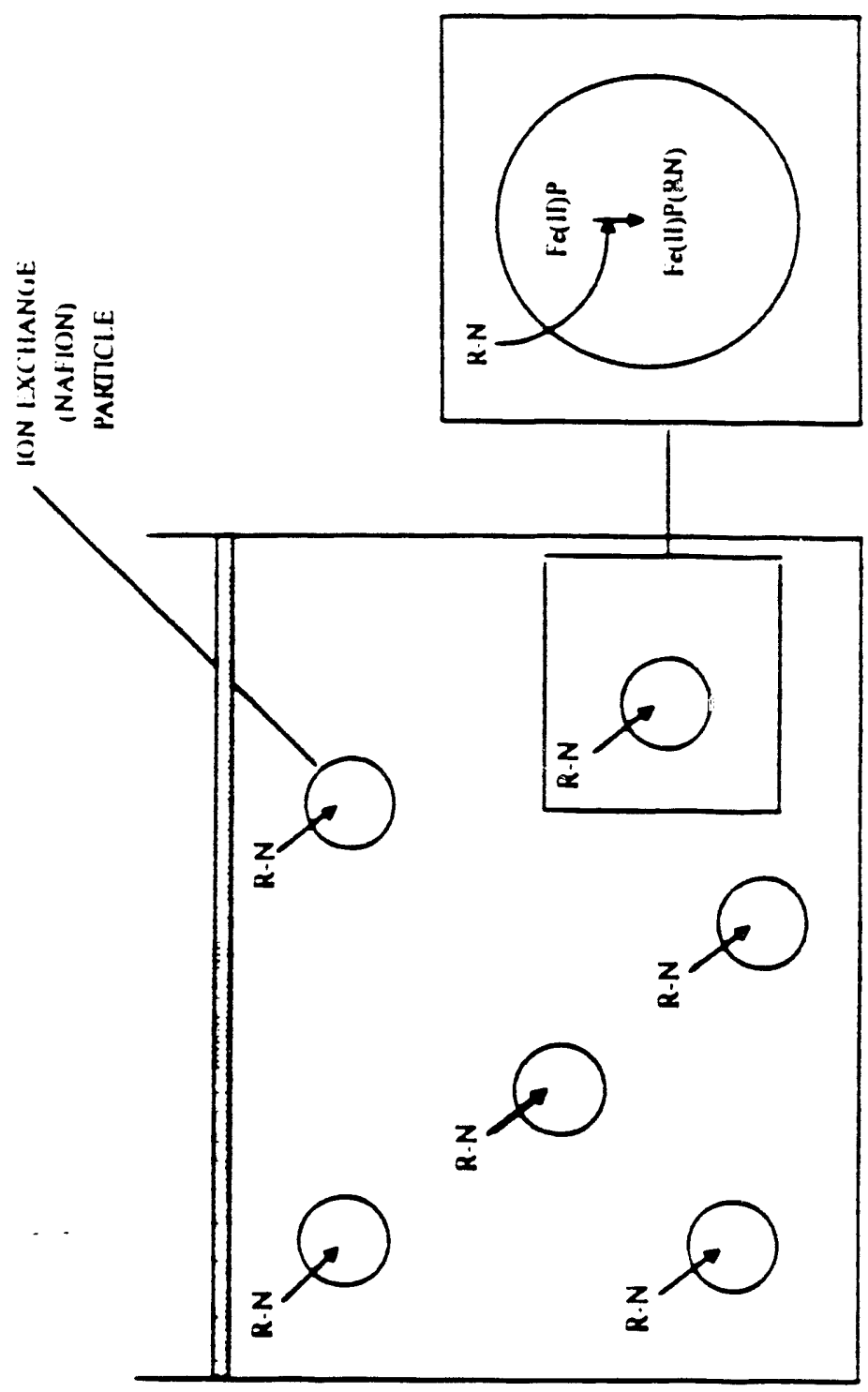

Figure 2 


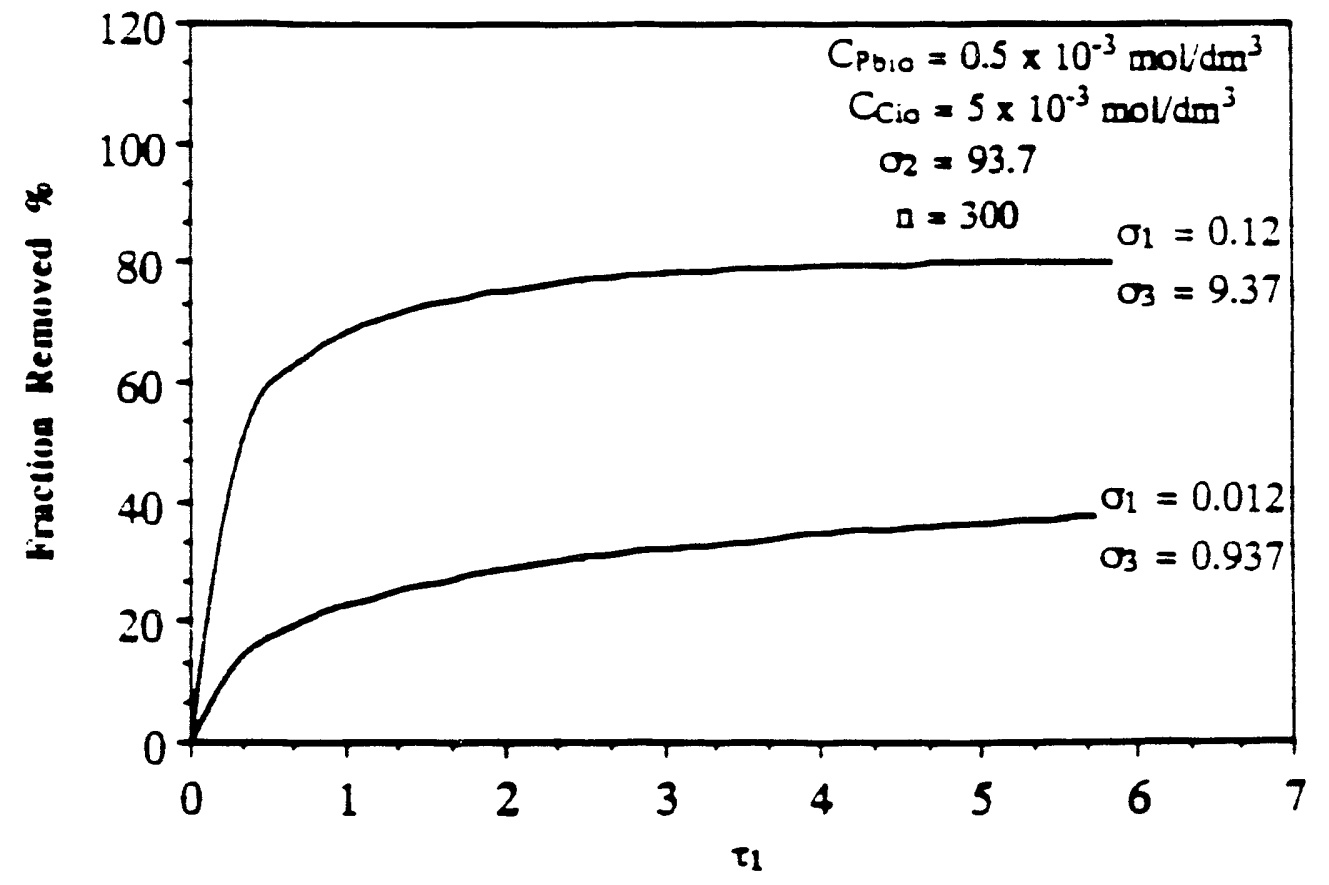

Figure 3 


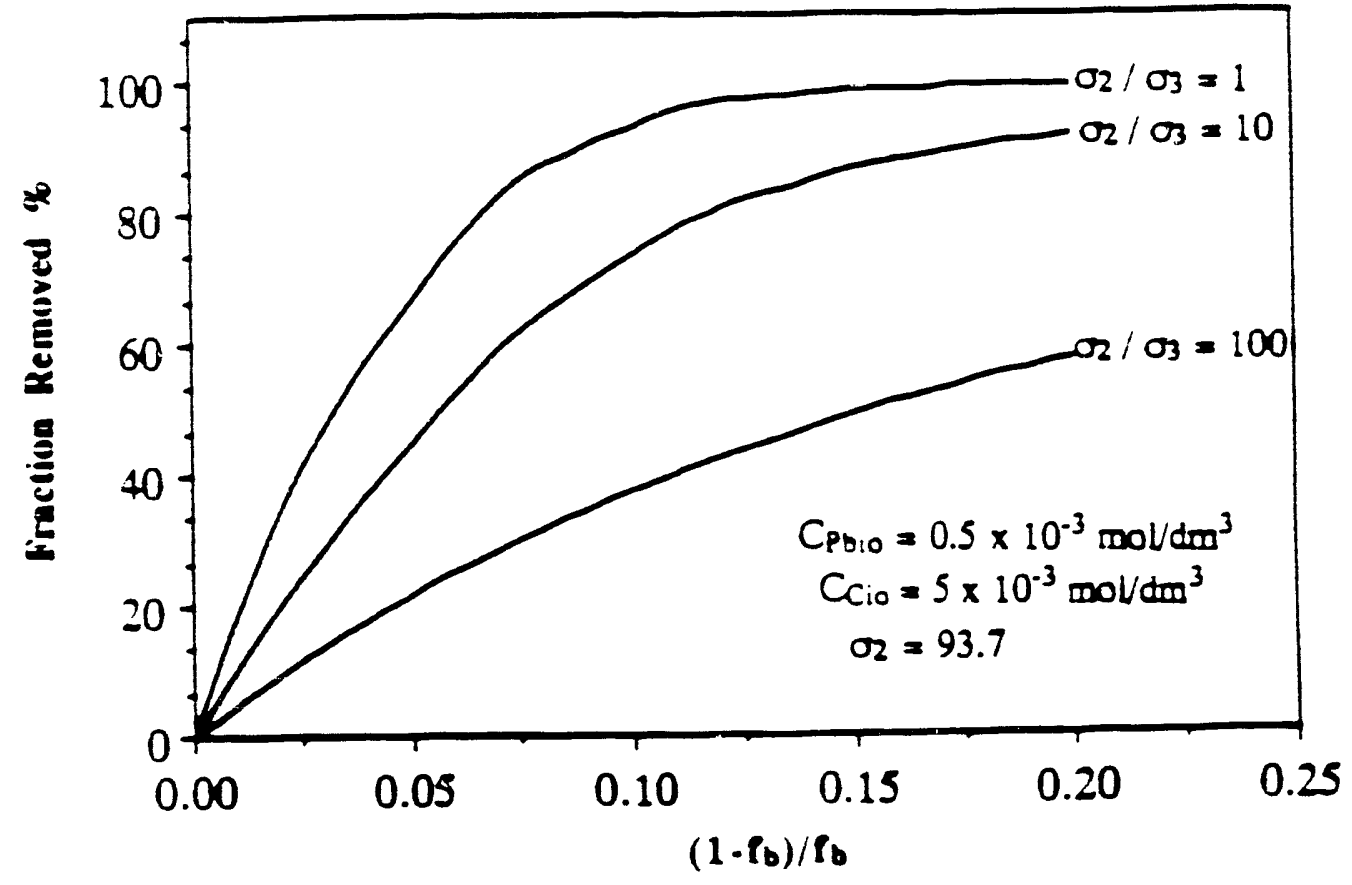

Figure 4 


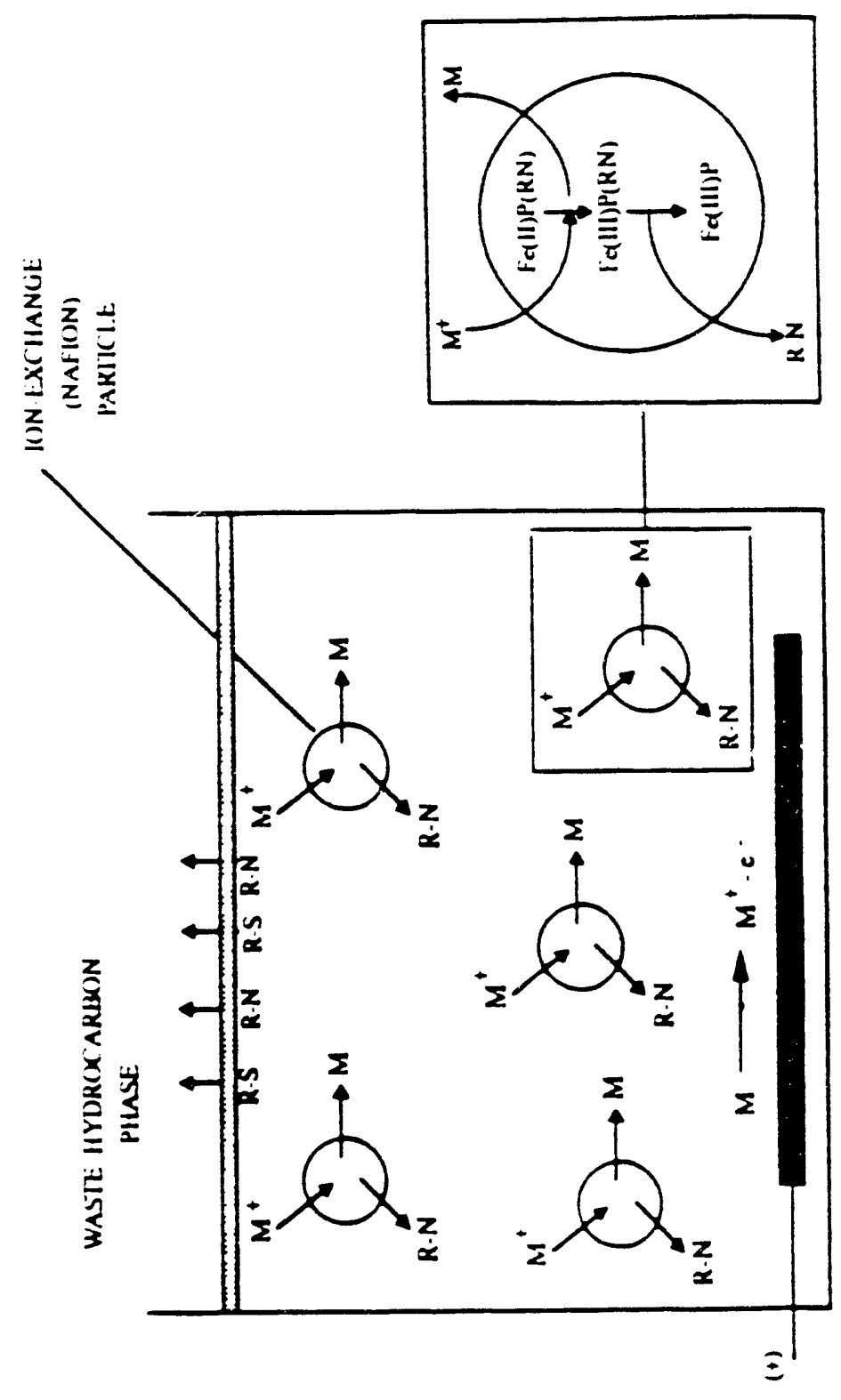

Figure 5 


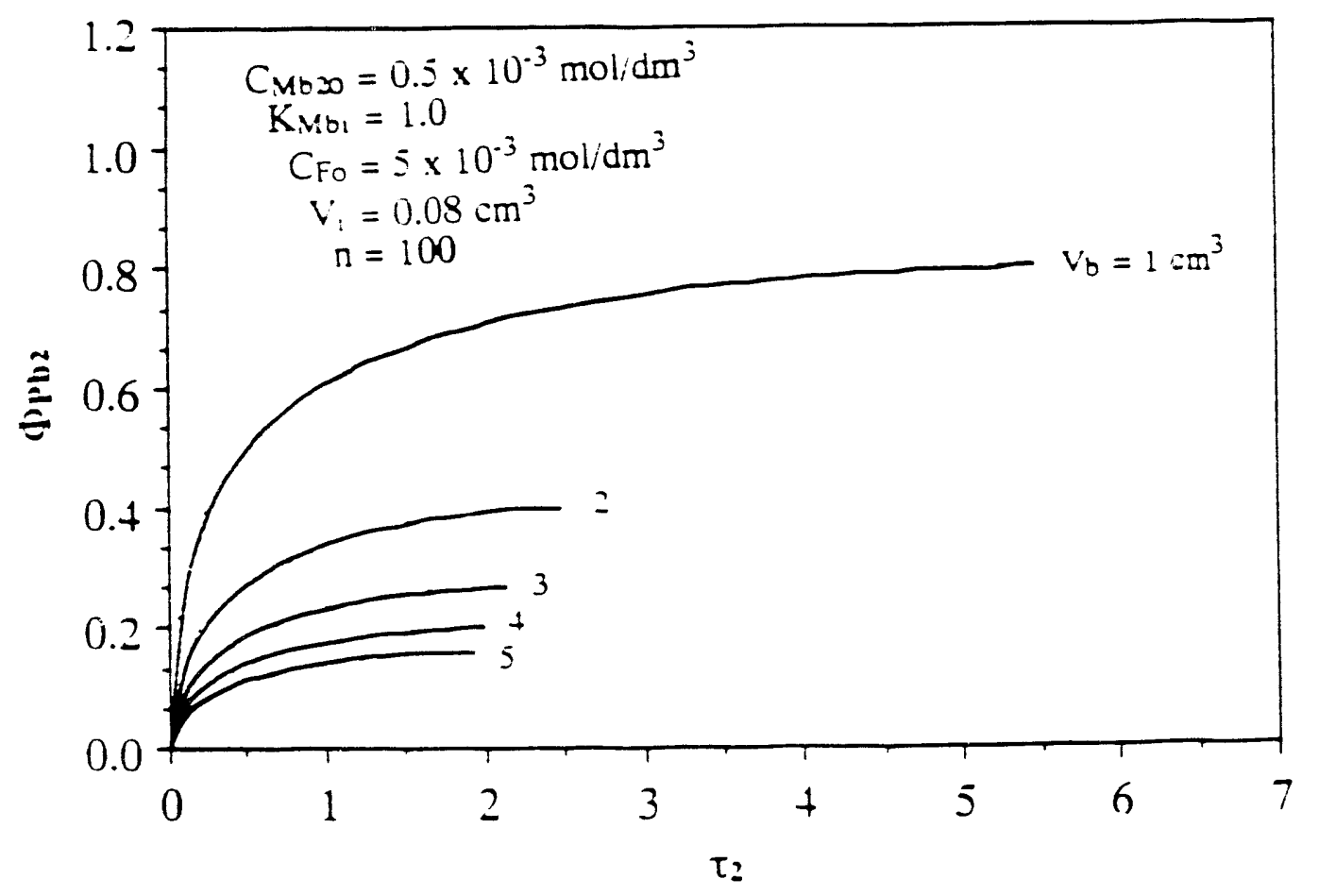

Figure 6 


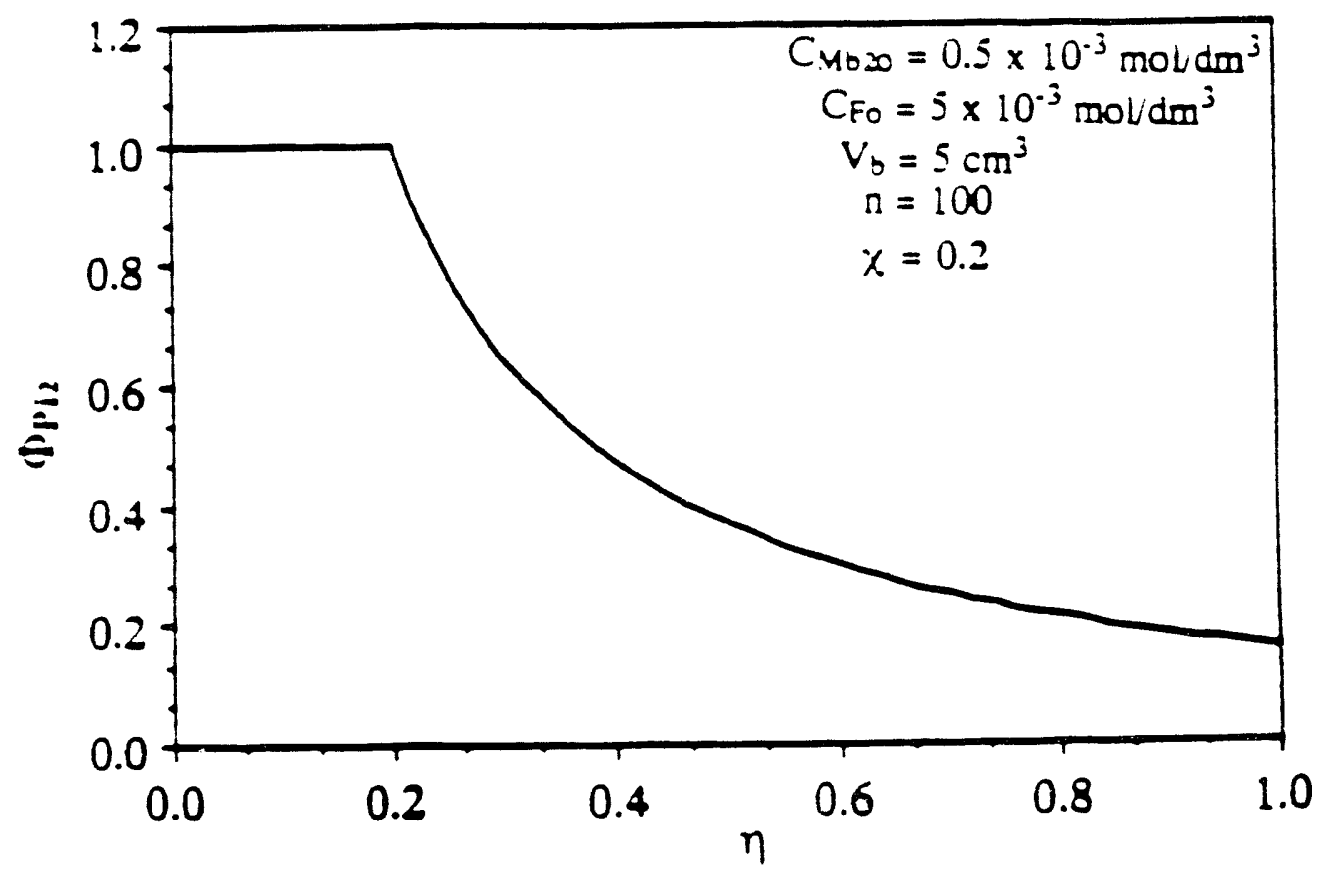

Figure 7 


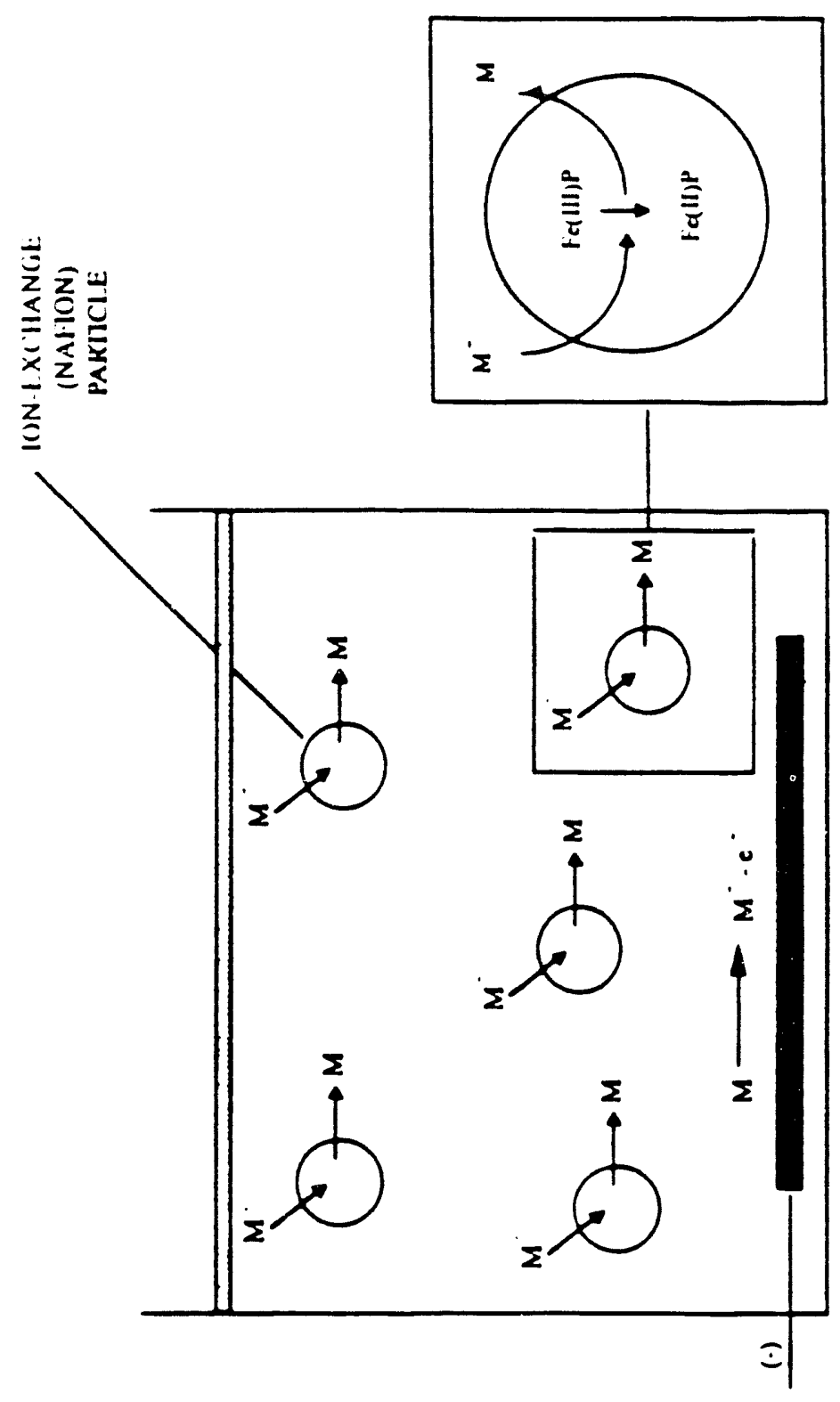

Figure 8 


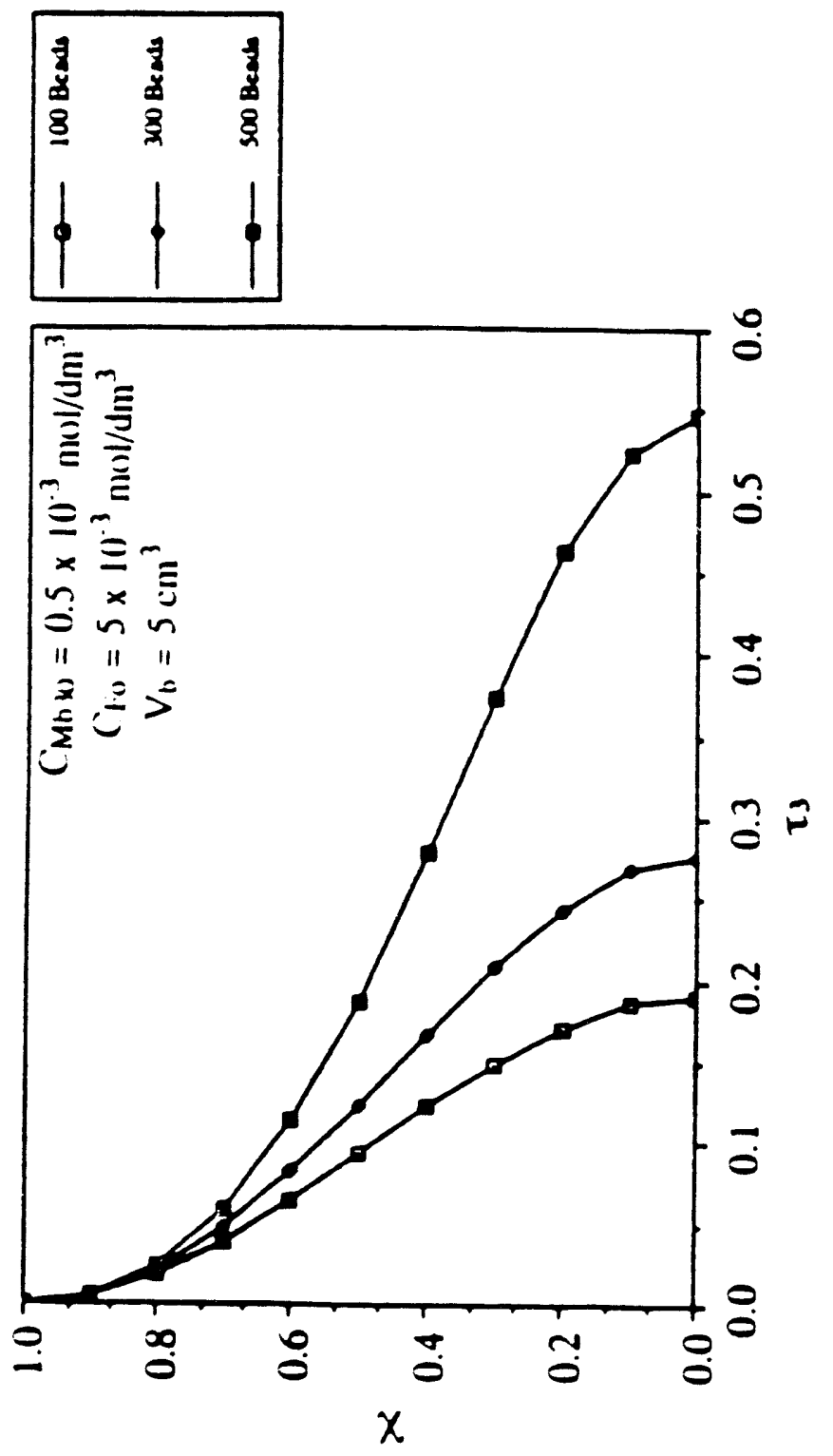

Figure 9 

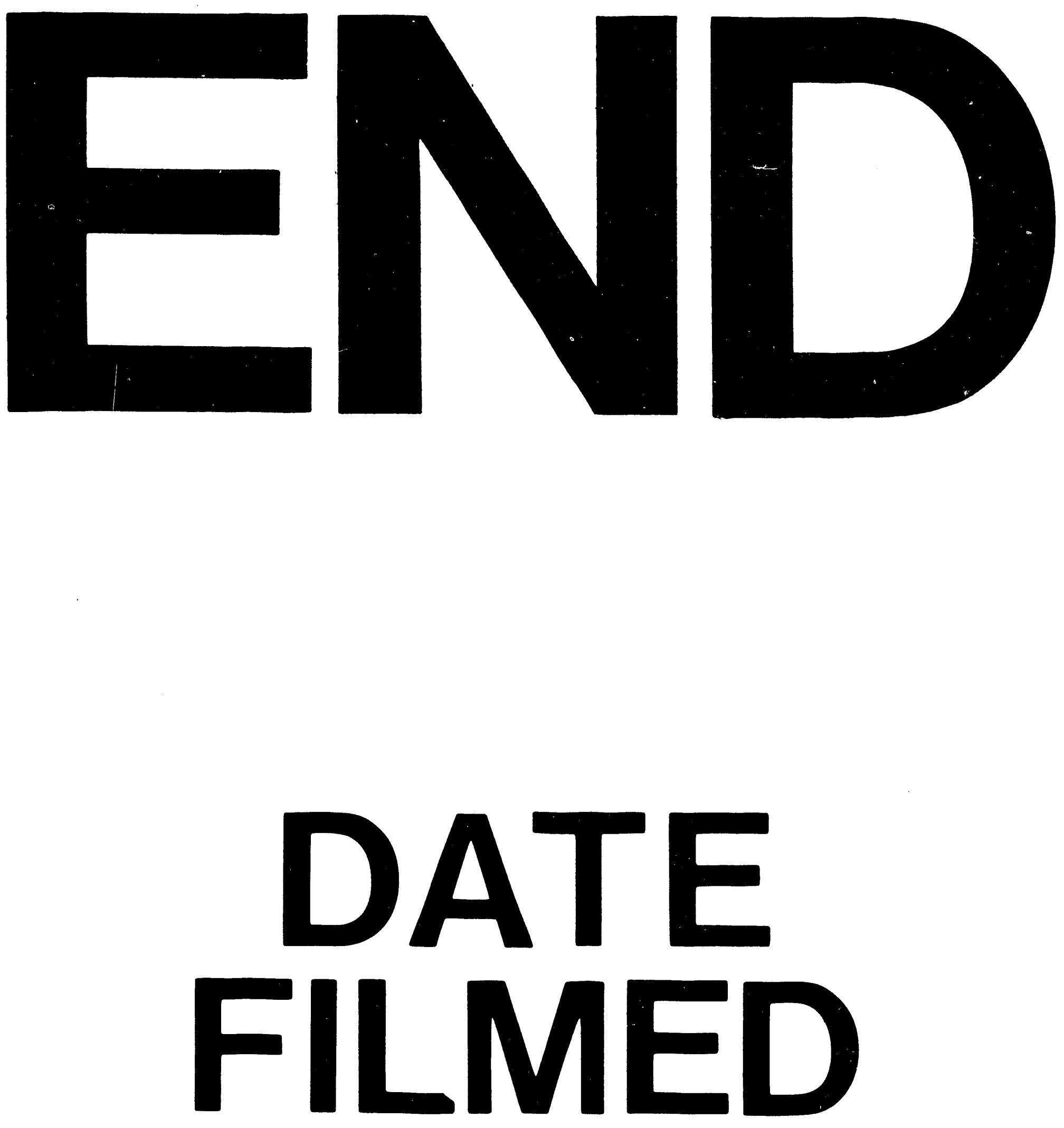

1

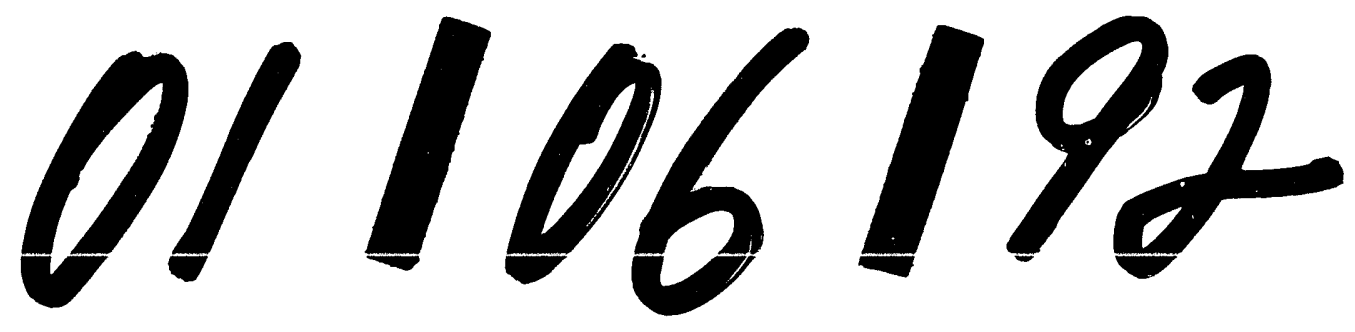


